\title{
Influences of Cultural Dimensions on Obstetric Health in Northern Bangladesh
}

\section{Md. Bokul Hossain ${ }^{1 \rtimes}$ \\ Md. Siddiqur Rahman ${ }^{2}$ Tanzima Zohra Habib}

${ }^{\prime}$ Lecturer, Department of Sociology, Varendra University, Bangladesh Email:bokulhossain2625@gmail.com Tel:+8801759584280

'Professor, Department of Sociology, University of Rajshahi, Bangladesh.

Email:siddik2008@gmail.com Tel: +8801757957641

${ }^{3}$ Professor, Department of Social Work, University of Rajshahi, Bangladesh.

Email:shomiswnus@yahoo.com Tel:+8801924813929

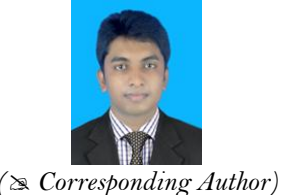

( Corresponding Author)

\section{Abstract}

The present study attempts to explore the cultural dimensions that influence obstetric health in suburban areas in northern Bangladesh. Mixed methods were used to conduct the present study. One hundred and twenty-five (125) respondents were selected through purposive sampling; all the female respondents had given birth within the last two years. Additionally, twenty (20) case studies and five (5) key informants' analysis were conducted in this regard. The research findings showed that some sociocultural factors such as patriarchy, conservative attitudes towards female gender, food taboos, high workload, shyness and taboo around gynecological and obstetric health issues, and perception of women being a family burden influenced obstetric health adversely. Also, many other cultural practices regarding obstetric health were noticed to have influenced obstetric health in the area in various other ways.

Keywords: Culture, Patriarchy, Food taboo, Over workload, Culture of shyness, Culture of being burden, Obstetric health. JEL Classification: I 19 Health: Other.

Citation | Md. Bokul Hossain; Md. Siddiqur Rahman; Tanzima Zohra Habib (2020). Influences of Cultural Dimensions on Obstetric Health in Northern Bangladesh. Asian Journal of Social Sciences and Management Studies, $7(4):$ 258-264.

History:

Received: 5 June 2020

Revised: 14 July 2020

Accepted: 17 August 2020

Published: 9 September 2020

Licensed: This work is licensed under a Creative Commons Attribution 3.0 License $($ (c) $)$ E

Publisher: Asian Online Journal Publishing Group
Acknowledgement: All authors contributed to the conception and design of the study.

Funding: This study received no specific financial support

Funding: This study received no specific financial support.
Competing Interests: The authors declare that they have no conflict of interests.

Transparency: The authors confirm that the manuscript is an honest, accurate, and transparent account of the study was reported; that no vital features of the study have been omitted; and that any discrepancies from the study as planned have been explained.

Ethical: This study follows all ethical practices during writing.

\section{Contents}

1. Introduction

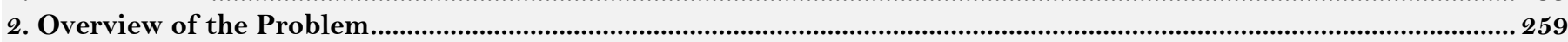

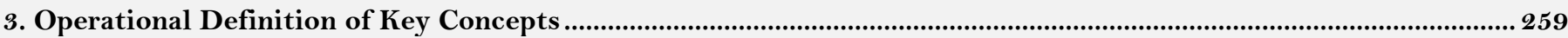

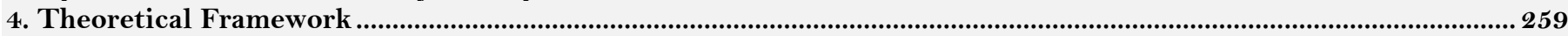

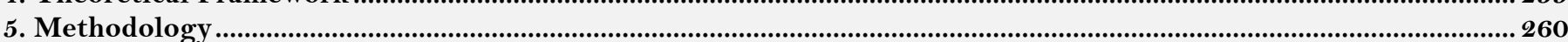

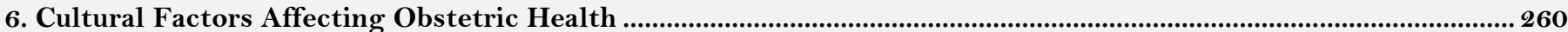

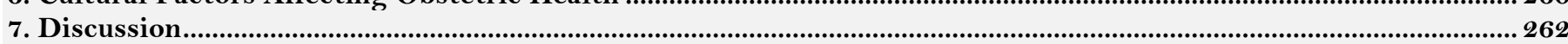

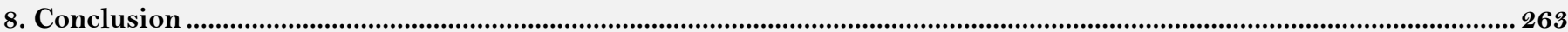

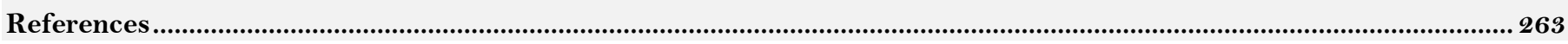




\section{Contribution of this paper to the literature}

The paper attempts to portray the adverse effects of different cultural factors on obstetric health of the respondents.

\section{Introduction}

Health is a holistic concept (Park, 2009). According to the World Health Organization (1946) "Health is a state of complete physical, mental and social well-being and not merely an absence of disease or infirmity." Within the discussion of health, obstetric health is very important. It is related to maternal mortality ratio (MMR) which is now widely considered as crucial indicators of the overall health status of a country. Over the last two decades of the past century, women's health issues have attained higher international visibility and renewed political commitments (Global Health Council, 2000). The international communities have constantly stated its commitment to decrease the high levels of maternal mortality in developing countries. Many initiatives have been taken through different conferences (the 1987 Safe Motherhood Conference in Nairobi, Kenya; the 1990 World Summit for Children at United Nations Headquarters; the 1994 International Conference on Population and Development in Cairo, Egypt; the 1995 Fourth World Conference on Women in Beijing, China; 'Nairobi 10 Years On' in Sri Lanka in 1997; the Millennium Development Goals in 2000; and The Sustainable Development Goals established by the United Nations in 2105) throughout the world (World Health Organization, 2009). These initiatives have been trying to enable women to live a healthy life by developing different policies and programs.

Despite these attempts many cultural factors have influenced women's health, especially obstetric health in various ways. Among the cultural factors patriarchy, conservative attitude towards female gender, food taboos, heavy workload, the culture of shyness, and cultural perception of being burden have been taken into consideration in this study. A number of studies on factors influencing obstetric health care have been reviewed and the various cultural factors that were found to impact such health included gender, religion-based cultural practices, literacy and language barriers, shared cultural similarities across different religious faiths, gender role expectations in a patriarchal society, traditional medicines and spiritual healers (Pir),malnutrition and risky birth practices (Adamu \& Salihu, 2002; Dennis, Fung, \& Grigoriadis, 2007; Emily, 2013; Khanum \& Taufikuzzaman, 2012; Lowe, Chen, \& Huang, 2016; Shole, 2017; Walton \& Schbley, 2013). Some authors Bryman (2016); Tuckman (1999) have pointed out that generally three kinds of research gaps are observed through literature reviews: data or contextual gap (lack of up-to-date data or studies in particular social context), methodological gap (lack of proper methods or sample used in previous studies) and theoretical gap (lack of theoretical footings as to the explanation of the phenomenon). The present study was conducted in the backdrop of data or contextual gaps. Therefore, the purpose was to assess the cultural dimensions of obstetric health in northern Bangladesh. The findings are expected to be helpful in policy making to acquire the goal-3 of Sustainable Development Goals (SDGs).

\section{Overview of the Problem}

Many women die and suffer from various preventable complications every year all over the world. Though different reports regarding obstetric health have shown major achievements in obstetric health fields (Bangladesh Ministry of Health and Family Welfare, 2015, 2017; World Health Organization, 2019)obstetric health complications is still a main cause of death among women in developing countries like Bangladesh. According to the World Health Organization (2019) while motherhood is often a positive and fulfilling experience, for too many women it is associated with suffering, ill-health, and even death. The major direct causes of maternal morbidity and mortality include hemorrhage, infection, high blood pressure, unsafe abortion and obstructed labor. Many factors like education, place of residence, occupation, maternal age, number of living children, gravid, marital status, religion, and ethnicity (Asundep et al., 2013; Dahal, 2013; Emily, 2013; Khanum \& Taufikuzzaman, 2012; Lowe et al., 2016; Mathe, 2017; Ogundairo \& Jegede, 2016; Shole, 2017; Simkhada, Teijlingen, Porter, \& Simkhada, 2008; Stella \& Adesegun, 2009; Ye, Yoshida, Harun-Or-Rashid, Sakamoto, \& Sakamoto, 2010; Zakar, Zakar, \& Itani, 2011) contribute to obstetric complications. Among these, cultural factors are also very crucial. Culture is a part and parcel of human life and cultural practices are more pervasive and deeply rooted than most other elements of society. It cannot be changed overnight. Therefore, the researchers intended to explore the cultural factors that affect obstetric health to acquire goal-3 of the Sustainable Development Goals. The researchers present the findings in this paper about how and to what extent cultural factors influence obstetric health in northern Bangladesh.

\section{Operational Definition of Key Concepts}

The following concepts are defined to clarify the connotation they reflect in this paper:

Obstetric Health: It refers to the health of women during pregnancy, childbirth and postpartum or postnatal period.

Culture: It is understood as the ideas, customs and social behaviors of a particular group. From a holistic perspective, "culture... is that complex whole which includes knowledge, beliefs, art, morals, law, customs, and any other capabilities and habits acquired by a man as a member of society (Tylor, 1871)." In the present study as well as in this paper, culture refers to the practices related to obstetric health including patriarchal norms, common socialization process, food taboos, gender roles, rituals regarding childbirth, etc.

\section{Theoretical Framework}

The present study is related to the field of Medical Sociology. A good number of theoretical propositions are available in the field of Sociology. But almost all the well-known sociological theories are constructed in the social contexts of developed countries. Those theories cannot be applied directly or completely to explain the facts and phenomena of a developing country. It may take more than one theory to explain a fact of developing country. In the context of Bangladesh, certain theories seem to create more controversies and confusion, and fail to explain local sociocultural complexities. Therefore, cultural bound theory and pathway model have been used as theoretical framework in this paper. 
Yap (1951) and Lambo (1955) pioneered the work on cultural dimensions of health and illness among the people of non-industrial societies (Erinosho, 1998). According to these pioneers' opinion, health and disease are to a large extent shaped by culture. As they have theorized, health, diseases and curative measures are to some extent shaped by prevailing culture of the people. Since culture is super organic and individuals have no reality of their own outside their culture, culture to a reasonable extent determines the total ways of life. In relation to this study, patriarchal and conservative attitudes towards gender, food taboos, over workload, the culture of shyness about obstetric care and cultural perception of being a burden in the family - all are cultural issues which determine individuals' patterns of interaction within the social system and in turn enhance their adaptability and mastering of the environment. Individuals' ability to reason out their own social reality pertinent to reproductive health and choice of foods are constrained within the norms and values of the society (Onabanjo \& Nwokocha, 2012). The present researchers wanted to understand the cultural factors affecting obstetric health particularly in the context of the study area in light of this theory.

Suchman was the first to use the pathway model to describe the various steps in the process of healthcare seeking from the identification of symptoms to the use of particular healthcare providing facilities. This model aims to identify a logical sequence of steps (The University of British Columbia, 2015). Rosenstock (1966) 'Health Belief Model' is also a pathway model. Glanz, Rimer, and Lewis (2002) and the National Cancer Institute (NCI) (2003) state that this model is by far the most commonly used theory in health education and health promotion. The Health Belief Model $(\mathrm{HBM})$ is a psychological model that attempts to explain and predict health behaviors. There are seven constructs of the Health Belief Model. Each of these perceptions, individually or in combination, can be used to explain health behavior. The first four constructs were developed as the original tenets of the Health Belief Model. The last three were added as research about the Health Belief Model evolved. These constructs are perceived severity, perceived susceptibility, perceived benefits, perceived barriers, modifying variables, cues to action, self-efficacy. In this study, the researchers aimed to understand the influence of different cultural factors on the different stages of the Health Belief Model.

\section{Methodology}

The present research was exploratory in nature and used both qualitative and quantitative methodologies. A social survey, as well as a case study method has been used in the present study. A checklist, questionnaire, tape recorder, and mobile phone have been administered as tools of data collection. Due to the nature of the present study, a combination of interview, in-depth interview and empirical observation have been used as the techniques of data collection. In other words, the objectives of the present study determined these techniques of data collection. Data was collected mainly from the primary source. A secondary source was also been included to strengthen primary data. The researchers purposefully chose ward no.30 of Rajshahi City Corporation of Bangladesh as a study area. This ward consists of seven colonies named Budpara, Mohonpur, Mirzapur, Choddopai, MaskataDigi, Behas and Rajshahi University. For identifying the population of the given area, a baseline survey was conducted and it was found that the total number of households was approximately 2,700 and the number of women who had delivered within the last two years was 1,212. It was 613 in 2016 and 599 in 2017 (EPI). It is censured by the local government and the community health center situated in the study locale. Among those 1,212 women who had delivered within the last two years, 125 were selected through purposive sampling as sample by using the sample size calculator of the Australian Bureau of Statistics (ABS) which recommends $10 \%$ of the total population (Confidence Level $=95 \%$, Population Size $=1212$, Proportion $=0.1$, Confidence Interval $=0.05$, Confidence Interval: Upper $=0.15000$ and Lower $=0.05000$, Standard Error $=0.02551$, Relative Standard Error $(\mathrm{RSE})=$ 25.51, Sample Size= 125). The individuals have been considered as the unit of analysis in this study. Besides, twenty (20) case studies and five (5) key informant analyses have been performed. Cultural factors that affect obstetric health have been explained based on the individual. The present research had been carried out for a period of three months and data was collected through a period of 29 days from 23 January 2018 to 20 February 2018. The researchers used various statistical methods such as tabulation, classification, frequency distribution, percentage, coding, measures of mean, different measurement scale for processing and analyzing the primary data. Two computer software (Microsoft Office Excel-2007 and Statistical Packages for the Social Sciences (SPSS)-20) was used for the interpretation and presentation of the obtained data. This paper presents findings of the research originally conducted for the academic purpose of completing an MSS thesis. A certificate has been issued by the thesis supervisor approving the ethical conducts of undertaking the research in the context of Bangladesh.

\section{Cultural Factors Affecting Obstetric Health}

According to Bierstedt and Bierstedt (1970) holistic understanding, "Culture is that complex whole that consists of everything we think, do and have as members of society."It is said that culture includes all the positive and negative aspects of human life. All aspects of human life are influenced by the culture of a given society. Obstetric health is a vital as well as critical and sensitive period of women's life. It is also influenced by different aspects of culture. Bloom, Wypij, and Gupta (2001) found that tradition also dictates women's experience of obstetric care and that women rely on traditional medicines and spiritual healers. The researchers in this study observed that some elements of the local culture such as patriarchal notions, conservative attitudes regarding gender roles, food taboos, workload, the cultural practices that reflect shyness and attitudes towards women as burdens influenced the obstetric health of the women in many ways. The influences of the different cultural factors on obstetric health found in the study are explained below:

\subsection{Patriarchy}

Patriarchy is the term which always indicates the rule of men, not just over women but also over the general structure of social relations. The term is therefore about the power of men, a power which extends to the individual jurisdiction of men (or a man) over a family and its members, as well as the more general power of "the male" over the organization of a social group or a society (Turner, 2006). Patriarchy affects obstetric health in different ways as presented and discussed below: 


\subsubsection{Lack of Decision Making Power}

The family structure of the Indian subcontinent is patriarchal in nature. For this reason, women's opinion in the family decision is largely ignored. This situation has a great impact on obstetric health.

Table-1. Lack of decision making power in family.

\begin{tabular}{c|c|c}
\multicolumn{3}{c}{ Table-1. Lack of decision making power in family. } \\
\hline Decision Making Power in Family & Frequency (f) & Percentage (\%) \\
\hline Yes & 21 & 16.8 \\
\hline No & 104 & 83.2 \\
\hline Total & 125 & 100.00 \\
\hline
\end{tabular}

Despite the multiple ways women contribute to their families, they often hold unfavorable and unequal positions in the household. For example, the above Table 1 shows that the majority of the women in this study did not have the power or liberty to make a family decision. Most of the respondents (83.2\%) reported that their opinion was ignored in making a family decision like having a baby or the total number of children, the marriage of children and so on. Only $16.8 \%$ respondents said that their opinion was valuable in the making of a family decision. As most of the respondents did not have control over family decisions, they worked without pleasure. It happens even during pregnancy and postpartum period. It also happens even for decisions about taking treatment for illnesses. The following table shows the respondents' status in making such decisions:

Table-2.Lack of decision making power in the family about receiving treatment.

\begin{tabular}{c|c|c}
\hline Decision Making Power in Receiving Treatment & Frequency (f) & Percentage (\%) \\
\hline Yes & 16 & 76.19 \\
\hline No & 5 & 23.81 \\
\hline Total & 21 & 100.00 \\
\hline
\end{tabular}

About $76 \%$ of the 21 respondents, who reported having a voice in making a family decision, also had the ability to make decisions by themselves about receiving a treatment whereas $23.81 \%$ reported not making a decision in this regard Table 2. Through the case study of a woman named Lakshmi Rani, it was evident that women have no freedom to stop their daily activities without the advice of a medical practitioner in the study area (Viz. case study4). They have to perform their household chores according to the will of their husband or family head. A 25 years old woman in the study looked much older like a 45 years old woman. She referred to the wrinkles on her face and said that the continuous household works even during pregnancy impacted her look. Another woman named Sarmin Begum said that they really work very hard (Viz. Case Study-6). In the remote area of Northern Bangladesh, there is no free time even for pregnant women and for new mothers just after giving birth within a week.

\subsubsection{Process of Socialization}

The socialization process of the respondents' family tends to be dominated by patriarchal values wherein female family members are taught to tolerate all kinds of violence against them. Many proverbs like "patience has its reward" are regularly taught to promote such kinds of patriarchal values.

\subsubsection{Attitudes towards Gender}

In the study area, people maintain conservative ideas about different gender roles for men and women. It is also a result of patriarchal culture. It also affects obstetric health among women adversely. Because of such conservative attitudes, women do not get opportunities to make decisions about their self-care and wellbeing, treatment, and workload.

\subsubsection{Authority in Procuring Consumer Goods}

Usually the male member of a family was found to be in charge of deciding what food items should be bought or prepared to be consumed because the consumer goods are brought by the male member of the family. It is a result of the patriarchal norm that hinders women to go to the market in most rural areas including the area of the current study. Onabanjo and Nwokocha (2012) reported that men's choice of foods have significantly influenced their wives' choice of foods and eating patterns, before and during pregnancy; this is similar to the findings of the present study.

\subsection{Heavy Workload of Women in Family}

In a family, a woman works from morning till night. There is hardly any break for women even during pregnancy and postpartum period. There is no chance to relieve their domestic chores unless it is advised by health personnel.

Table-3. Performance of household work during the period of pregnancy, childbirth and postnatal phase

\begin{tabular}{c|c|c}
\hline Performing Household Work & Frequency $(\mathbf{f})$ & Percent (\%) \\
\hline Yes & 45 & 36.0 \\
\hline No & 80 & 64.0 \\
\hline Total & 125 & 100.0 \\
\hline
\end{tabular}

Women are usually exempted from performing hard work, especially heavy weight lifting work during pregnancy and the postpartum period. it tends to create obstetric complications. But findings of this study Table 3 showed that $36 \%$ of respondents had performed heavy and hard work during pregnancy and even postpartum period. Though $64 \%$ women did not perform any hard work during pregnancy and postpartum period, a significant number of women, as high as $36 \%$, bore the risks of growing obstetric complications. It was observed by the researchers that drinking water is collected and fetched exclusively by women in the study areas. In many ways, these household tasks prevent women from seeking health care in the earlier stages of their pregnancies. Women 
have to perform many risky and hard menial works during pregnancy, childbirth and postpartum period within the family without the help of others. This is detrimental to their health. This phenomenon is shown in the table below.

\begin{tabular}{c|c|c} 
Table-4. Getting Assistance with Household Work during the period of pregnancy, childbirth and postnatal phase. \\
\hline Getting Assistance with Work & Frequency (f) & Percent (\%) \\
\hline Yes & 35 & 28.0 \\
\hline No & 90 & 72.0 \\
\hline Total & 125 & 100.0 \\
\hline
\end{tabular}

The period of pregnancy, childbirth and postnatal stage is very sensitive and crucial for a woman's overall health and wellbeing. We should take good care of women through this sensitive period as much as possible, at least for the continuation of the human race. But most of our respondents did not get an optimum care. The Table 4 shows that $72 \%$ of the respondents did not get any assistance from others in performing their daily household work. They said that family members helped them for a few days only during the childbirth period. Beyond that, they performed all the tasks of maintaining the entire household on their own. On the other hand, $28 \%$ respondents received some assistance with their household work during the whole period. Many of them got help from relatives and a few others kept a housemaid as a paid helper during the period.

\subsection{Observing Food Taboo}

The Table 5 shows that most of the respondents (52.8\%) had faced barriers or restrictions to eating certain foods during pregnancy, childbirth and postpartum period.

Table-5. Food Taboos in the Study Area.

\begin{tabular}{c|c|c}
\multicolumn{3}{c}{ Table-5. Food Taboos in the Study Area. } \\
\hline Observing Food Taboo & Frequency (f) & Percent (\%) \\
\hline Yes & 66 & 52.8 \\
\hline No & 59 & 47.2 \\
\hline Total & 125 & 100.0 \\
\hline
\end{tabular}

On the other hand, $47.2 \%$ respondents did not have such kinds of problem. The food taboo during this period is a great problem and it creates the platform for many of the complications related to obstetric health such as infection, hemorrhage, urological dysfunction and pelvic pain. Besides, many of the respondents did not even receive iron tablets. Such cultural practice leads to malnutrition which is the root of many obstetric complications. In this connection, we must consider BMI. The normal range of the body mass index (BMI) is $19-25$ and it is a widely used indicator of overall health. The national average BMI of Bangladeshi women is $<18.5$, which is considered considerably underweight and belongs to the category of malnourished. Malnutrition potentially compounds the previously existing problems during the prenatal and postpartum periods (NIPORT, 2001). A survey of 26,424 pregnant women in Bangladesh found that $35-38 \%$ of pregnant women had a body mass index of less than 18.5, they weighed $48-49 \mathrm{~kg}$, and over $50 \%$ of them were suffering from severe iron deficiency or anemia (Faruque, Ahmed, \& Ahmed, 2008).

\subsection{Culture of Shyness}

Shyness is one of the major cultural traits found in the study areas. Shyness means anxious reactivity in challenging social situations. Although shyness is believed to be biologically rooted, individual's socialization experiences play a vital role in shaping its development (Chen, 2019). The respondents acknowledged the adverse effect of the culture of shyness on obstetric health. Those who belonged to extended families were especially suffering because of the headship of the father-in-law in the family. Besides, the respondents who gave birth for the first time were affected more severely by this practice.

\subsection{Cultural Perception of Being a Burden}

The respondents in general said that they didn't share every problem with the male members for the fear of being considered a burden of the family. That is why they often had to hide their obstetric health-related problems from their family. Such a culture affects obstetric health adversely.

Besides the factors mentioned above, there are many other cultural beliefs and practices regarding obstetric health which impart significant influences on obstetric health. As per the definition of obstetric health behavior, these cultural practices can also be considered as obstetric health behavior. Some of these cultural practices for example, restrict pregnant women and new mothers from moving around during the time of noon and evening, eating certain foods, keeping hair open or loose and exposed. Pregnant women often carry a chilly in her bag when they go outside the house; some also carry a pin or nail made of iron in their hair braids or buns when they go outside the house. A terracotta pot with coal fire is often kept in the room where a woman gives delivery; the window of the delivery room is surrounded by fishing net; a firebox is kept beside the head of a newborn child. These are some examples of the superstitious cultural practices around pregnancy and childbirth prevalent in the area of the current study.

\section{Discussion}

Culture has a great influence on obstetric health. Different cultural practices affect women's health adversely during pregnancy, childbirth and postnatal period. Patriarchy provides the fuel behind these cultural practices that keep women behind. This work is done through some social processes. Abstaining women from the decision-making process of the family, holding conservative and negative attitudes towards female gender, faulty socialization and unequal treatment of female children are some of these common processes. Most of the respondents in this study did not have the power to provide an opinion in the process of making a family decision. Intentionally or unintentionally, they always abstained themselves from this process. Even the decision about receiving care and treatment related to obstetric health is taken by the male members of the household. Besides, during pregnancy, 
childbirth and postnatal period their daily routines and lifestyle are also decided by the husband. In addition to this, the people of the study area are very conservative in regards to particular gender roles. They also raise and socialize their children by strictly following these patriarchal values.

The maintaining of the whole family by women is also a cultural practice of the study area. Especially those who belong to a nuclear family suffer from more difficulties because the women have to perform all the family and daily household activities by themselves from dawn to dusk. Women's health, especially obstetric health is influenced adversely by such kind of workload. In the study area, drinking water for a family is collected from tube-well by women only. Even during the period of pregnancy women perform this task which is very dangerous and harmful for their health; but this work can be easily performed by a male member of a family. This shows their adherence to the traditional gender division of labor deeply rooted in the culture of patriarchy. As a result of the heavy workload, women go through a very critical process during pregnancy period. Moreover, sometimes such kinds of workload prevent them from receiving ANC (Anti Natal Care) visit which is a very important and desirable obstetric health behavior.

Food taboo during pregnancy is a very common cultural practice in Bangladesh. Women refrain from taking nutritious food because of it. Such kind of food taboo affects mother and child health adversely during pregnancy and postnatal period. The respondents said that they did not take iron tablets because of the food taboo. Family members of the respondents told them that it is harmful to take any medicine without any disease, even if it is iron tablets. Besides, they did not take adequate food for maintaining sound health because of certain food taboo. It causes malnutrition which is a big problem in a country like Bangladesh. Almost all people are suffering from malnutrition; however, women are suffering more than men. It creates many health-related problems. It may be concluded that food taboo creates malnutrition through refraining women from taking adequate food which is the root cause of many obstetric complications.

Shyness is a major trait of the culture of the study area. Respondents could not share their obstetric problems with the family members because of such shyness. Women, especially those who gave birth for the first time, suffered from this problem more compared to others. Besides, female members in extended families encountered more of such kinds of cultural problems. Thus, the culture of shyness along with the existing social perception of women being a family burden affects obstetric health adversely.

There are many cultural practices regarding obstetric health and those practices exert significant negative influences on obstetric health. Thesepractices around pregnancy and childbirth can also be considered as obstetric health behavior. Most of these behaviors are superstitious and dominated by local cultural beliefs and practices. Expecting and new mothers are made to abide by these potentially risky obstetric health behaviors. Even the respondents in this paper obeyedthese cultural practices though most of them did not know the logic behind it. They said that they learned these practices from their respective families and society at large, and they did not try to know the logic behind it. Some women also said that they inherited these knowledge and practices from their fore-bearers. Question about the logic of these cultural practices does not rise in their mind. Further study can be conducted to explore the logic of such kinds of cultural practices regarding obstetric health. Some influences or connections of religion may exist behind these health practices and obstetric health behaviors. The study respondents were also practicing some religious mores regarding pregnancy, childbirth and postpartum phase. The Muslim women visited shrines to pray for their unborn or newborn children. They performed different religious rituals more often during these times than at other times. For example, they also donated money, food and other valuable things to the madrassah or mosques as well as monks. On the other hand, Hindu women mentioned worshiping particular gods or goddesses for their babies. They also pertained to their baby like Muslim women did. Both Muslim and Hindu families arrange an occasion named 'shad' as a religious vogue in the study area.

\section{Conclusion}

The current study found that some socio cultural factors such as patriarchy, heavy workload and food taboo during pregnancy and obstetric periods, the culture of shyness and the social perception of being a family burden affected obstetric health of the research participants adversely in the study area. Moreover, different cultural practices rooted in patriarchy and prejudices create significant unfavorable effects on obstetric health. Patriarchy as a social norm and cultural factor affects obstetric health negatively through abstaining women from partaking in the family decision-making process, maintaining conservative attitudes towards female gender and socializing children by following patriarchal values. Women's heavy workload in the household influenced obstetric health negatively through obligating them to perform hard work like fetching water during pregnancy and postpartum period and refraining them from receiving ANC visits and TT vaccination. Food taboo also affected obstetric health adversely by creating malnutrition. Some other influential factors that affected women's obstetric health and health behaviors adversely included the culture of shyness to speak up against oppressive norms, and the traditional view of women as liability. Moreover, there are many cultural practices and religious vogue in the study area and those also influenced obstetric health of the respondents in many ways. In these circumstances, the government of Bangladesh should emphasize on health education to protect women's obstetric health from the adverse effects of cultural factors. This will help the nation to achieve the goal- 3 of the Sustainable Development Goals.

\section{References}

Adamu, Y., \& Salihu, H. (2002). Barriers to the use of antenatal and obstetric care services in rural Kano, Nigeria. Journal of Obstetrics and Gynaecology, 22(6), 600-603. Available at: https://doi.org/10.1080/0144361021000020349.

Asundep, N. N., Carson, A. P., Turpin, C. A., Tameru, B., Agidi, A. T., Zhang, K., \& Jolly, P. E. (2013). Determinants of access to antenatal care and birth outcomes in Kumasi, Ghana. Journal of Epidemiology and Global Health, 3(4), 279-288. Available at: https://doi.org/10.1016/j.jegh.2013.09.004

Bangladesh Ministry of Health and Family Welfare. (2015). Health bulletin 2015. Dhaka: : Government of the People's Republic of Bangladesh Ministry of Health and Family Welfare.

Bangladesh Ministry of Health and Family Welfare. (2017). Health bulletin 2017. Dhaka: Government of the People's Republic of Bangladesh Ministry of Health and Family Welfare.

Bierstedt, R., \& Bierstedt, R. (1970). The social order. New York: McGraw-Hill. 
Bloom, S. S., Wypij, D., \& Gupta, M. D. (2001). Dimensions of women's autonomy and the influence on maternal health care utilization in a North Indian city. Demography, 38(1), 67-78. Available at: https://doi.org/10.1353/dem.2001.0001.

Bryman, A. (2016). Social research methods. Great Clarendon Street UK: Oxford University Press.

Chen, X. (2019). Culture and shyness in childhood and adolescence. New Ideas in Psychology, 53, 58-66. Available at: https://doi.org/10.1016/j.newideapsych.2018.04.007.

Dahal, R. K. (2013). Utilization of antenatal care services in rural area of Nepal. International Journal of Collaborative Research on Internal Medicine E̊ Public Health, 5(2), 120-132.

Dennis, C., Fung, K., \& Grigoriadis, S. (2007). Traditional postpartum practices and rituals: A qualitative systematic review. Women's Health, 3(4), 487-502. Available at: https://doi.org/10.2217/17455057.3.4.487.

Emily, E. C. (2013). A review of cultural influence on maternal mortality in the developing world. Midwifery, 29(5), 490-496. Available at: https://doi.org/10.1016/j.midw.2012.04.002.

Erinosho, O. A. (1998). Health sociology. Ijebu-Ode, Nigeria: Bulwark Consult.

Faruque, A. S. G., Ahmed, A. M. S., \& Ahmed, T. (2008). Nutrition: Basis for healthy children and mothers in Bangladesh. Journal of Health Population Nutrition, 26(3), 325-339.

Glanz, K., Rimer, B. K., \& Lewis, F. M. (2002). Health behavior and health education (3rd ed.). San Francisco: Jossey-Bass.

Global Health Council. (2000). The importance of womens health. In: C.S, Atama, Ed., Socio-Cultural Factors Affecting Maternal Health: A Study of Owukpa Community, Ogbadigbo L.G.A, Benue State and Obolloeke Community, Udenu L.G.A, Enugu State. Retrieved from http://www.unn.edu.ng/publications/files/images/mummy\%20final\%20\%20\%20\%20\%20work.pdf.

Khanum, S. M., \& Taufikuzzaman, M. (2012). Constrains on women's access to emergency obstetric care in Bangladesh. Dhaka: University Grants Commission, Bangladesh.

Lambo, T. A. (1955). Traditional African cultures and western medicine: A critical review. In FNL Poynter (Ed.) Medicine and Culture (pp. 201-210). London: Wellcome Institute.

Lowe, M., Chen, D.-R., \& Huang, S.-L. (2016). Social and cultural factors affecting maternal health in rural Gambia: An exploratory qualitative study. PloS One, 11(9), e0163653. Available at: https://doi.org/10.1371/journal.pone.0163653.

Mathe, M. (2017). Socio-demographic factors affecting utilization of antenatal care services in Botswana. International Journal of Academic Research in Business and Social Sciences, 7(9), 477-520. Available at: https://doi.org/10.6007/ijarbss/v7-i9/3343.

National Cancer Institute (NCI). (2003). Theory at a glance: A guide for health promotion practice. Washington, DC: : U.S. Department of Health and Human Services.

NIPORT, O. (2001). Bangladesh maternal health services and maternal mortality survey.

Ogundairo, J. A., \& Jegede, A. S. (2016). Socio-cultural challenges in accessing antenatal care by pregnant fulani women in Ibarapa central local government, Oyo-State, Nigeria. Annals of Public Health and Research, 3, 1043-1044.

Onabanjo, D., \& Nwokocha, E. E. (2012). Socio-cultural correlates of food intake among pregnant women in Ijebu-East, South Western, Nigeria. Ilorin Journal of Sociology, 4(1), 57-74.

Park, K. (2009). Preventive and social medicine. Jabalpur: Banarsidas Bhanot.

Rosenstock, I. M. (1966). Why people use health services. Milbank Memorial Fund Quarterly, 83(4), 1-32. Available at: https://doi.org/10.1111/j.1468-0009.2005.00425.x.

Shole, R. N. (2017). An impact of socio-cultural practices on maternal mortality in Masasi District, Tanzania. Malaysian Journal of Medical and Biological Research, 4(1), 47-58. Available at: https://doi.org/10.18034/mjmbr.v4i1.424.

Simkhada, B., Teijlingen, E. R., Porter, M., \& Simkhada, P. (2008). Factors affecting the utilization of antennal care in developing countries: A systematic review of the literature. Journal of Advanced Nursing, 61, 244-260. Available at: https://doi.org/10.1111/j.13652648.2007.04532.x.

Stella, B., \& Adesegun, F. (2009). Determinants of use of maternal health services in Nigeria-looking beyond individual and household factors. BMC Pregnancy and Childbirth, 9, 1-13. Available at: https://doi.org/10.1 186/1471-2393-9-43.

The University of British Columbia. (2015). UBC. Retrieved from: https://wiki.ubc.ca/Health_Seeking_Behaviour.

Tuckman, B. W. (1999). Conducting educational research (5th ed.). New York: Harcount Brace College Puplisher.

Turner, B. S. (2006). The Cambridge dictionary of sociology. UK: Cambridge University Press.

Tylor, E. B. (1871). Primitive culture: Researches into the development of mythology, philosophy, religion, art, and custom (Vol. 2). London: J. Murray.

Walton, L. M., \& Schbley, B. (2013). Cultural barriers to maternal health care in rural Bangladesh. Online Journal of Health Ethics, 9(1), 1-13. Available at: http://dx.doi.org/10.18785/0jhe.0901.03.

World Health Organization. (1946). Constitution of the world health organization. Paper presented at the International Health Conference, New York, 19-22 June 1946.

World Health Organization. (2009). Monitoring emergency obstetric care a handbook. Geneva: WHO Press, World Health Organization.

World Health Organization. (2019). Maternal health. Retrieved from http://www.wpro.who.int/cambodia/topics/maternal_health/en.

Yap, P.-M. (1951). Mental diseases peculiar to certain cultures: A survey of comparative psychiatry. Journal of Mental Science, 97(407), 313327. Available at: https://doi.org/10.1192/bjp.97.407.313.

Ye, Y., Yoshida, Y., Harun-Or-Rashid, M., Sakamoto, J., \& Sakamoto, J. (2010). Factors affecting the utilization of antenatal care services among women in Kham District, Xiengkhouang province, Lao PDR. Nagoya Journal of Medical Science, 72(1-2), 23-33.

Zakar, R., Zakar, M., \& Itani, T. (2011). Factors associated with use of maternal health care services in Pakistan: Evidence from DHS Pakistan. Social Science \& Medicine, 68, 1349-1356. Available at: https://doi.org/10.1055/s-0031-1283690. 